\title{
The challenge of multi-channel transactions
}

\author{
Judy Lilley \\ established Pro tem. Publications Solutions in 1998, to offer an independent resource to assist businesses develop \\ multi-channel production and marketing techniques, specializing in publication production systems and workflow \\ selection, the implementation of new technologies and change management, including customized training and \\ production support. Judy is a qualified printer and manager with more than 25 years' experience within the catalog \\ and mail order industry, covering both business-to-consumer and business-to-business markets. She is a member of the \\ Institute of Paper, Printing and Publishing and was elected to the Consultants Register in 2001. She is also an \\ associate consultant for the Applied Expertise Group.
}

Keywords: publishing systems, multi-channel publishing, dynamic restructuring, digital asset management (DAM), content management systems (CMS), product management

Abstract Customer buying patterns and transactions force business to develop existing channels and implement new ones to suit their marketplace. Technology is secondary, in that it is merely the tool to help deliver these transactional requirements. The need to have digital assets easily accessible by everyone from brand and price, to product and service information, to sound and video is critical to market position.

Judy Lilley

Pro tem. Publications

Solutions

Blacksmiths Yard

Lower Road

Little Hallingbury

Herts CM22 7RD, UK

Tel: +44 (0)1279

722487

Fax: $+44(0) 1279$

723884

Email: info@pro-tem.net

\section{INTRODUCTION}

Business today relies on a multitude of networks and technology, and it often appears that this is what drives the development of commerce. This is a major misconception, as the only drivers of commerce are customers. It is customer buying patterns and transactions that force business to develop existing channels and implement new ones to suit their marketplace. Technology is secondary, in that it is merely the tool to help deliver these transactional requirements. That said, however, the channels can only develop in line with the advances in technology. Speed to market and accurate product information is crucial and this where digital asset management
(DAM) and content management systems (CMS) come to the fore.

\section{EVOLVING BUYING PATTERNS}

Traditional channels like face-to-face, point of sale (POS), telephone and mail services have expanded with web, emarketing, mobile applications, kiosks, interactive television and games. Channel hopping is here to stay, maintained by a number of factors:

- Choice and preference: Customers can browse products on the internet, print off information, view in store, then order by phone from a printed catalog for home delivery, at a time that suits them.

- Communication breakdown: Where websites have poor or complex 
functionality or printed information is incomplete or confusing, this pushes customers to use other channels or other companies.

- Telecommunications: Both of the above factors cause customers to pick up the phone; developments around mobile applications will continue to feed these interactions.

The impact is that call center traffic continues to increase and retail has seen a reduction in footfall. Circulations of printed catalogs and brochures are decreasing whereas versions; specialogues — themed or specific-range publications - and variable print techniques are on the increase. The implementation of effective customer relationship management (CRM) systems and strategies is more critical than ever to provide the data to plot customers' cross-channel buying patterns.

The world is changing and business is finding it hard to comprehend the multi-channel mix in a holistic way. This is primarily due to the way that the channels evolved and the timeframes associated with the technology.

\section{THE NEED FOR CONVERGENCE}

Businesses have implemented and developed separate systems for each channel at different times, using a variety of data sources or data-based architectures, all supported by the traditional departmental team structure. For example, we see marketing departments controlling the print channel and IT departments controlling the website or electronic channels. Thus, each channel maintains a proportion of duplicate data, specific teams and, in part, duplicate processes, which all has an impact on efficiencies, costs and accuracy. It is still true today, although business and technology efficiencies have resulted in the convergence of skill sets, technologies and data, which will continue as multi-channel develops. The need to have all digital assets easily accessible by everyone from brand and price, to product and service information, to sound and video is critical to market position. With ongoing developments around DAM and CMS, single-source enterprise solutions are now available to all sizes of business.

The delaying factor has not been the reluctance to accept the new channel technologies, but the cost of research and development for providers, and return on investment for businesses running disparate systems and supporting infrastructures. To move to a single-sourced multi-channel structure, in the purest sense, is not just a case of upgrading or replacing existing publishing channels. It is about restructuring around a core system holding/viewing enriched product data that is fed with data from the various business systems dynamically outputting to each channel, or at worst, partly via data feeds. This requires a business to reorganize, with all the aspects of change management, to move from a parochial to a global view. A daunting prospect for any company to face, along with the high cost (both direct and indirect) that restructuring incurs, this has been a major barrier to the progression of multi-channel strategies. Any configuration will be severely hampered unless all the data are current and valid, however. The work involved in cleaning data from existing disparate systems to be used in a new structure is 


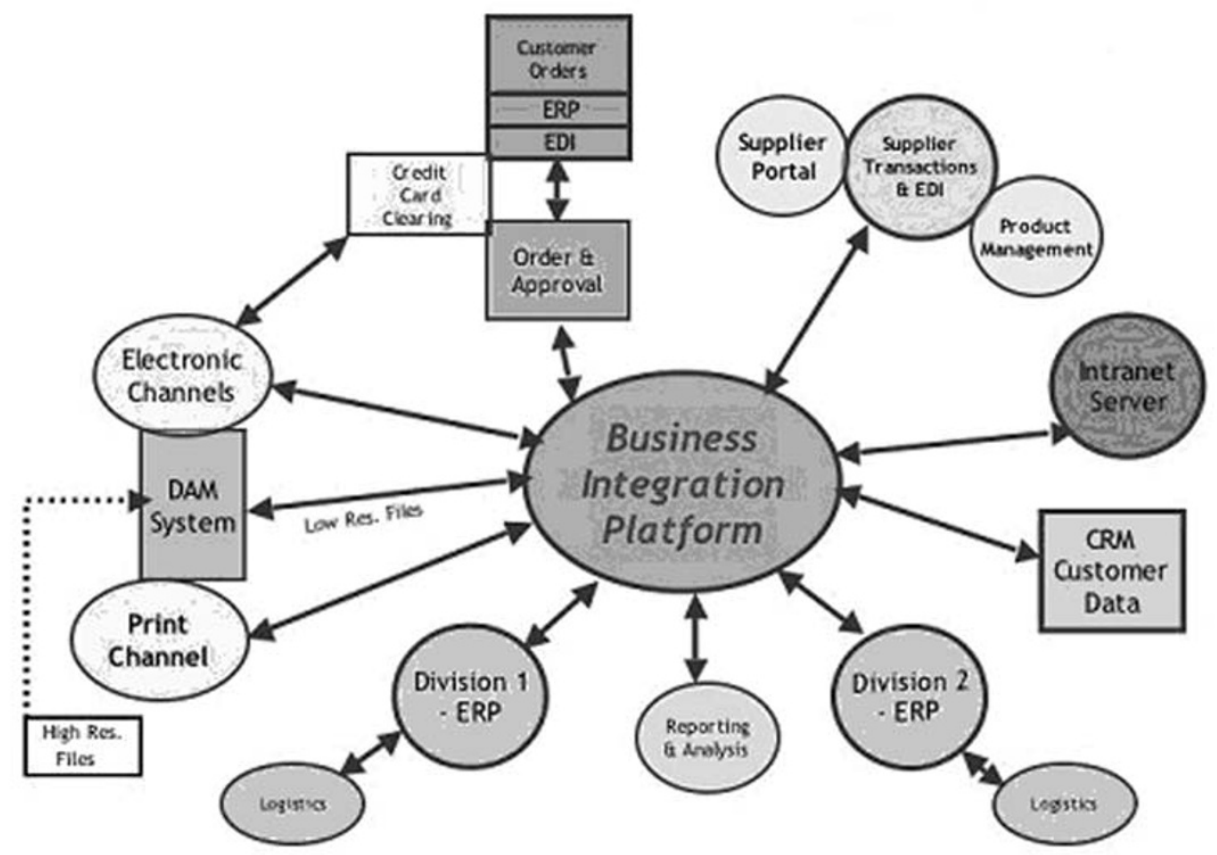

Figure 1: Example enterprise model

a huge task and must not be underestimated.

Each business is unique and the level of restructuring will depend on the disparate systems in use, the present functionality, scalability and costs. Figure 1 shows a hub configuration that uses existing data sources where possible, collating the required information for a particular user or channel. It basically acts as a data filter, so data are collated/ created once and then used many times. This illustrates why the cleanliness of data is critical, ensuring that the data are not only current but that any duplication is minimized through mirroring data.

A leading UK electrical products wholesaler selected this configuration to link the various enterprise resource planning (ERP), logistics and publishing systems that were in place. They used the central product information database to hold core product data and lowresolution images with paths to other business data repositories, highresolution images and other digital assets.

A future phase will develop the document handling functionality to create an intranet structure. As with all system implementations of this kind, the biggest task continues to be data cleaning process aligned to taxonomies, data classification and attributes.

\section{PUBLISHING SYSTEMS}

Content management, digital asset systems and publishing systems have been available for a number of years in a variety of forms and price tags.

Publishing systems in particular were primarily developed for the print channel, as standalone, data-based systems, generally working with partners to provide the e-channel routes as modules to the core systems. These take data feeds from, or links to CMS/ DAM systems and other business data sources, to extract product data and 
information. These data are then manipulated through functionality into page or e-channel formats, for output to the relevant channel.

These range from low-cost systems running $4 \mathrm{D}$ databases to the higher priced systems running on SQL and Oracle. They vary in degree of sophistication of cross-media publishing functionality.

Some examples of systems available in the UK:

- Catbase: CatBase Software Ltd. www.catbase.com

- Campaign: AO International www.ao-international.com

- Catalog'nTime: Lockside Software Ltd. -www.locksidesoftware.com

- Catalogger: Guidance Software www.guidance.nl

- CMS: Pindar - www.pindar.com

- K4: Productivity Computer Solutions www.pcs.com

- Matrix CMS: Matrix Software www.matrixsoftware.co.uk

- MediaMine: MediaMine Next Generation NV www.mediamine.com

- Quark DMS: Productivity Computer Solutions - www.pcs.com

- 65-bit: 65-bit Software Ltd www.65bit.com

There are also a few low-cost data link products that locate and direct data from incumbent data sources to design software such as QuarkXpress and InDesign or create feeds for e-channels.

\section{ENTERPRISE SOLUTIONS}

With regard to enterprise (multichannel) publishing models - this is an ambiguous area that in theory contains a multitude of systems. The majority of enterprise systems can output to print and/or electronic publishing systems using XML feeds etc, which have been available for a number of years. This means that once the data feed has been taken, the data are effectively obsolete. Many systems interface with customized modules for electronic publishing outputs because the data packets are small and the outputs can be structured.

With printed publications, however, the variables in the design and print process are extensive. It is easy to extract data to feed into design software such as QuarkXpress, InDesign or FrameMaker; the pages can then be made up manually, but there are no links remaining to the master data source(s) - a time-consuming and onerous process when hundreds of pages are required. Numerous extensions and plug-in software can be purchased to retain data links or provide additional functionality. Key extensions are price merges, indexes, table creators and autopagination, but there are others. On the downside, when the design software is upgraded, the extensions and plug-in software in use can become incompatible and work-arounds are required until new releases are available.

Enterprise publishing systems have developed interfaces not just to the electronic channels but also to the print channel. By structuring the data and building-in the page make-up features to integrate with the design software, to automate the process. This means that the business not only has control of its data and assets but also the routes to market. That is when a business cannot only react to customer buying patterns, but also, to a great extent, pre-empt the customers choice - a very powerful business tool. 
In the UK there are only a few that can be classified as enterprise publishing systems. The following cover established and newer entrants into the marketplace.

- ADAM: Alfaprint - www.ADAM.be The newest entrant offers a secure costeffective "hybrid" electronic publishing/ DAM structures system in line with multi-channel requirements. Its predecessor was a product called Phrasea, a media management system designed for the editorial market in the late 1990s. The system is now a versatile Microsoft SQL 2000 data-based content publishing middleware, developed from and with an understanding of single-sourced publishing requirements.

It can archive all kinds of digital assets including pictures, video, sounds, text, fonts, illustrations, QuarkXPress, InDesign documents and many others (Figure 2). It can integrate with Open DataBase Connectivity (ODBC)-enabled legacy ERP systems to gather and manage the assets that need publishing (from whatever source) directly, or via XML, to other systems. The data held in the ERP systems, remain in those systems, the system creates live crossplatform links (or views) and repurposes

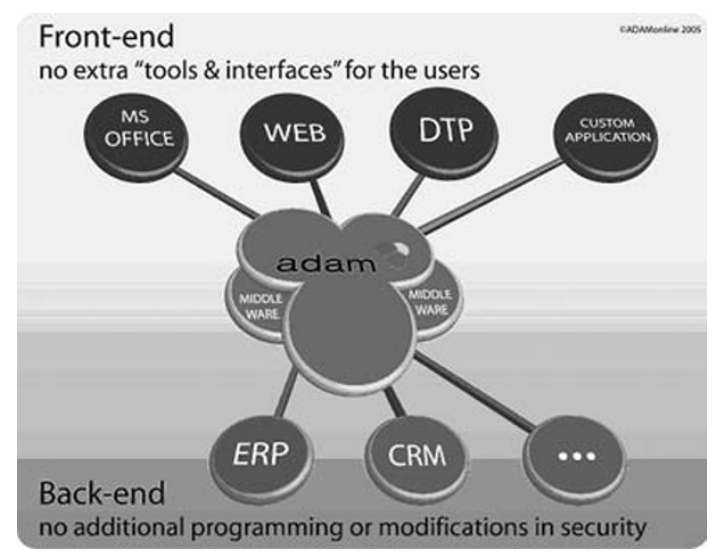

Figure 2: ADAM configuration the information as defined by the user. By linking business systems, pre-press production, proofing, production and creating an archive digital library, specific channel workflows can be set up. ADAM has been designed with a form of "intelligence," so novice users can easily find their way with built-in data validation, enrichment and classification functionality. More powerful users can build their custom applications with the software development kit (SDK). The system architecture and functionality mean assets can be searched, located and published as printed collateral or catalogs via the links to QuarkXPress or Adobe InDesign (which has the auto-pagination functionality). Publishing to the web is directly supported or via XML data feeds and can be customized further using the SDK.

The asset and product information management resources are fully browserbased, although the graphic design client is Mac OSX platform only. The functionality is variable depending on usage requirement but could act as the middleware/business integration platform as shown in the hub configuration. The system is in use in Europe by print and design companies, by Agfa in the imagery market, Puratos the food ingredient manufacturer and various other market sector businesses.

- Agility: Pindar - www.pindar.com Agility appeared about 2001 and continues to develop. It is a Java-based solution supporting IBM Websphere and BEA Web logic. It has a highly configurable product information management structure, and a "Content Gateway" module for dynamic links to business systems. The system supports Oracle or SQL databases and links to QuarkXpress 6.5 for page-building 
functionality. For bespoke development an application program interface (API) is available. Creative designs are developed and maintained as design templates within QuarkXPress into which product attribute data are semi-automatically uploaded from the database. This enables designers to amend data within Quark and to fine-tune page design to achieve the best page layout results. Product managers/database administrators have full access to product information and can easily edit or add data, build forthcoming publications and add page layout guidelines for the page make-up team to follow. The product hierarchy and product attribute selections are married together so that product managers are only asked for attributes relevant to the type of product they are adding. Office Depot, the US office stationery supplier, currently uses the system, as does the UK mail-order business Littlewoods.

- Stibo STEP: Stibo Catalog www.stibocatalog.com This is the established model evolving over more than 15 years from CCI technology, and the latest version (4.6) is a powerful business solution that manages product content across multiple

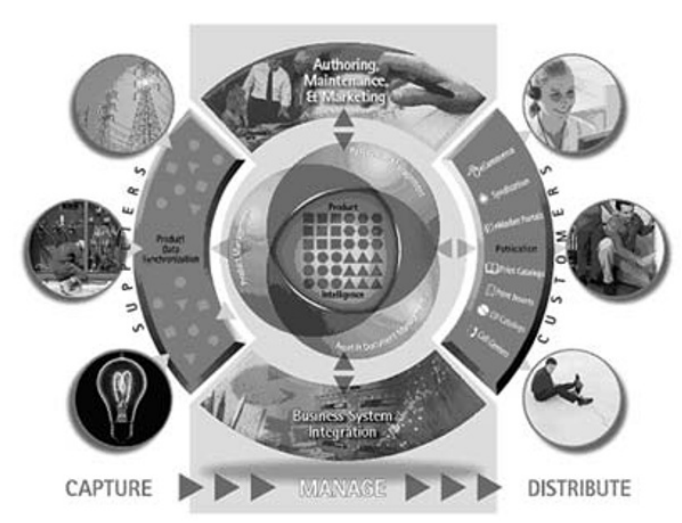

Figure 3: Stibo STEP configuration channels. The system supports Oracle and SQL databases and is organized in a three-tier architecture - a database layer, an application layer and a client layer - with each tier addressed via specific APIs. The SQL API opens up the abstract model of the database tier, the Java and XML APIs represent the business logic implemented in the application tier, and the plug-in APIs expand the options with the client components (Figure 3).

It is a powerful, flexible business solution that manages product content across the enterprise - from receiving raw data from product suppliers, via internal workflow processes across departmental lines, to the complete delivery of enriched product marketing content for multi-channel delivery, including print, web, e-procurement, CD-ROM and others. Product managers can use an automated planning and production process for multi-channel product promotions. Marketing professionals can manage the complex multi-channel and multilingual product catalog environment. Production staff can reuse information easily through to output into QuarkXPress 6, Adobe InDesign 2 and Adobe FrameMaker software. Information maintained in one location can be published or syndicated to as many targets as required. For the ebusiness environment the XML delivery of catalog content, incremental product updating of e-commerce sites, product deletion and other tools make it easier to receive and integrate multi-channel product content.

There are numerous installations worldwide but in the UK, Screwfix, the direct tool and building supplies business, and RS Components, the 
leading distributor of industrial and electronic products, have the system.

\section{TO THE FUTURE ...}

The configuration of functionality required by different companies will vary as will the complexity of functionality by channel. The key is finding the best-fit solution that meets the business requirements. The benefits are the control on business assets, products, suppliers and process to provide a cost-effective and efficient model that has a positive impact on the bottom line. For customers the benefits are better value, service and faster delivery. A truly "win-win" situation.

The present scenario in creating a multi-channel enterprise solution is that the business systems need to interface with CMS, DAM and publishing solutions to be fully functional. The multi-channel market will drive the convergence of system functionality to create true enterprise solutions for business irrespective of size, thereby reducing the present number of systems, processes and roles that a business requires.

The customer is key to this whole process and has to be the starting point in identifying the developments needed for current channels; then project and plan for future channel hopping combinations to maximize sales and margins.

Remember that the "customer is king," the challenge of multi-channel publishing is to sell the product and service that the customer wants - but through the channel of their choice and at the right price. 